\title{
Associations of streptococci and fungi amounts in the oral cavity with nutritional and oral health status in institutionalized elders: a cross sectional study
}

\author{
Hanako Sato ${ }^{1}$, Akira Yano ${ }^{2}$, Yu Shimoyama ${ }^{3}$, Toshiro Sato ${ }^{1}$, Yukiko Sugiyama ${ }^{1}$ and Mitsuo Kishi ${ }^{*}$
}

\begin{abstract}
Background: Disruption of the indigenous microbiota is likely related to frailty caused by undernutrition. However, the relationship between undernutrition and the oral microbiota, especially normal bacteria, is not obvious. The aim of this study was to elucidate the associations of nutritional and oral health conditions with prevalence of bacteria and fungi in the oral cavity of older individuals.

Methods: Forty-one institutionalized older individuals with an average age \pm standard deviation of $84.6 \pm 8.3$ years were enrolled as participants. Body mass index (BMI) and oral health assessment tool (OHAT) scores were used to represent nutritional and oral health status. Amounts of total bacteria, streptococci, and fungi in oral specimens collected from the tongue dorsum were determined by quantitative polymerase chain reaction (PCR) assay results. This study followed the STROBE statement for reports of observational studies.

Results: There was a significant correlation between BMI and streptococcal amount $(\rho=0.526, p<0.001)$. The undernutrition group $(\mathrm{BMl}<20)$ showed a significantly lower average number of oral streptococci $(p=0.003)$. In logistic regression models, streptococcal amount was a significant variable accounting for "not undernutrition" [odds ratio $5.68,95 \%$ confidential interval (Cl) 1.64-19.7 ( $p=0.06)]$. On the other hand, participants with a poor oral health condition (OHAT $\geq 5)$ harbored significantly higher levels of fungi $(p=0.028)$.

Conclusion: Oral streptococci were found to be associated with systemic nutritional condition and oral fungi with oral health condition. Thus, in order to understand the relationship of frailty with the oral microbiota in older individuals, it is necessary to examine oral indigenous bacteria as well as etiological microorganisms.
\end{abstract}

Keywords: Body mass, Oral health, Elder, Streptococci, Fungi

\section{Background}

Along with the general aging of society worldwide, frailty is gaining attention. This is a common geriatric syndrome that increases the risk of poor health outcomes, including

\footnotetext{
*Correspondence: mkishi@iwate-med.ac.jp

1 Division of Preventive Dentistry, Department of Oral Medicine, I wate Medical University School of Dentistry, 1-3-27 Chuo-dori, Morioka, Iwate 020-8505, Japan

Full list of author information is available at the end of the article
}

falls, functional disability, hospitalization, and mortality [1-3]. Epidemiological studies have shown high proportions of elder individuals with a frailty phenotype (weakness, slowness, unintentional weight loss, exhaustion, low physical activity) $[4,5]$. Since the cycle of frailty generally begins from chronic malnutrition and consequent weight loss [2], the health of the oral cavity, located at the start of the digestive tract, is likely related with a frail condition [6]. Previous studies have found relationships between 
malnutrition and poor oral health conditions in older individuals, in which dental disease status or oral function, including dental caries, periodontitis, tooth loss, and mastication, or swallowing disorders were mainly investigated as malnutrition risks [7-10]. In investigations that used a microbial approach, a relationship of the oral microbiome, consisting of not only pathogenic agents but also non-pathogenic indigenous bacteria, with nutritional status and oral health status has been demonstrated in older subjects $[11,12]$. It has also been shown that the indigenous oral microbiota, composed of various microorganisms, plays an important role in maintaining homeostasis of oral and systemic health [13]. In the oral cavity, indigenous microorganisms such as streptococci grow and develop a suitable microbiota based on the environment provided by the host [14]. Once the microbiota is established, it helps to protect the host from invasion by pathogenic microorganisms and subsequent infection $[15,16]$. Therefore, when a normal oral microbiota is disturbed, the population of pathogenic microorganisms is easily increased, which causes oral and systemic diseases [17]. On the other hand, the oral microbiota can be affected by changes in the oral environment as well as general conditions, such as aging, immunosuppression, and medication [18-20].

Recently, oral fungi have received focus as etiological microorganisms, especially in the elders, and it has been shown that older individuals are more prone to colonization by fungi due to such factors as decreased immune response, reduced salivary flow, and denture use [20-22]. Candida species, the most prevalent fungi found in the human oral cavity, are normal commensal and asymptomatic organisms in healthy conditions [23]. However, in frail older individuals or immunocompromised patients, it can overgrow in oropharyngeal or esophageal mucosa, which causes a burning sensation, taste disorder, severe mucositis, and/or dysphagia, resulting in poor nutrition $[24,25]$. Furthermore, even with the absence of such oral symptoms, a relationship of general malnutrition with certain fungi in the oral cavity of elderly individuals has been shown [26].

Fungal growth in the oral cavity as well as systemic malnutrition are thought to be associated with an alteration in prevalence of oral indigenous bacteria. Oral dryness is a condition that can enhance fungal growth, though is not suitable for growth of indigenous oral bacteria such as oral streptococci. In addition, a decrease in oral intake of food, which is generally the start of the frailty cycle, can have a negative effect on growth of oral streptococci, whose main energy source is carbohydrates from staple foods $[14,27,28]$. Thus, deterioration of general health and nutritional status may disrupt the normal microbiota by increasing fungi and decreasing indigenous bacteria amounts. Such an oral microbiome composition may increase problems with the teeth or oral mucosa, causing adverse effects on systemic nutritional intake. We speculated that simultaneous measurements of oral fungal and streptococcus levels would be useful for determining systemic and oral frailty. Although detailed analyses of the oral microbiota have been reported [29, 30], few studies that investigated fungi and bacteria analyzed those in the same oral specimens, due to different gene targets associated with the molecular microbiological methods used.

In the present study, the amounts of fungi, total bacteria, and commensal streptococci in tongue samples of institutionalized older individuals were determined, and systemic and oral conditions were assessed. From those results, the relationships of systemic nutritional condition and oral health status with oral microbial prevalence were investigated.

\section{Methods}

\section{Ethical considerations}

The study was performed according to the principles of the Declaration of Helsinki and was approved by The Ethics Committee of Iwate Medical University School of Dentistry (approval no. 01340). Individuals with decision-making ability were given information regarding the study protocol and enrolled as participants after providing documentation indicating consent. For those who lacked ability to make such a decision due to cognitive decline, study protocol information documentation was given to a closely related family member, who provided consent for participation. Individuals who refused to participate in the study survey or undergo analysis after providing consent were subsequently excluded.

\section{Study design and participants}

This was a cross-sectional observational study and conducted at a nursing institution located in Iwate Prefecture, Japan. Informed consent was obtained from 42 of the 160 residents. Exclusion criteria included administration of antimicrobial or antifungal drugs within one month of the survey, as well as current status of undergoing parenteral nutrition. None of the 42 residents who provided consent to participate met those criteria. However, at the time of the oral examination, one rejected participation, after which none withdrew their consent. Consequently, 41 elder individuals (8 males, 33 females) with an average age \pm standard deviation (SD) of $84.6 \pm 8.3$ years (range 70-105 years) completed the present study protocol (Fig. 1). None had a smoking or drinking habit. Two of the participants were undergoing special medical care, as one received dialysis treatment three times a week and the other wore a cardiac pacemaker, though neither presented outliers in regard 


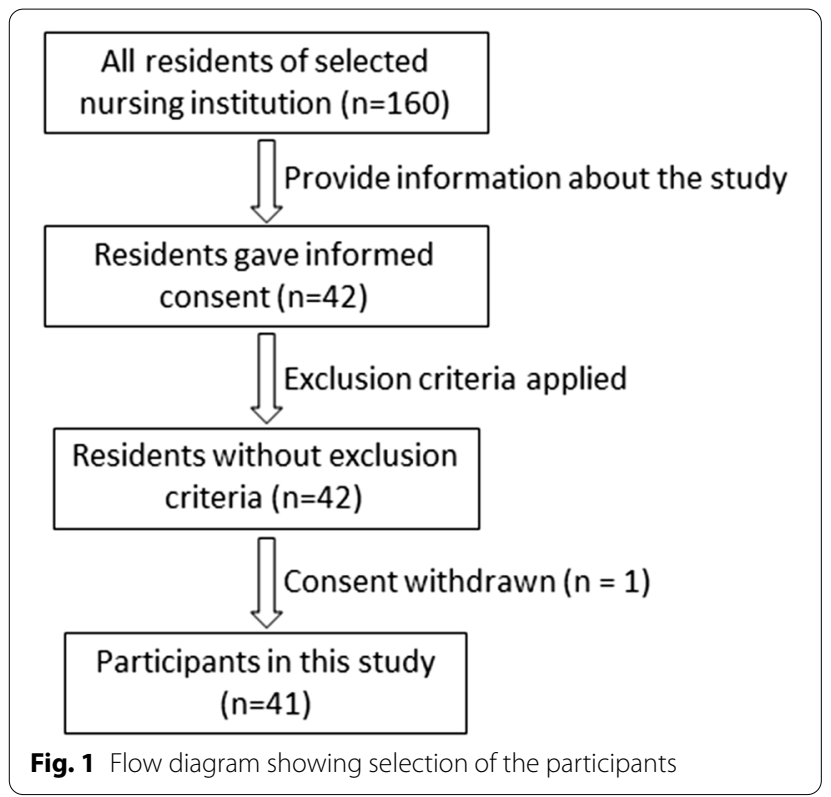

to body mass index (BMI), oral health assessment tool (OHAT) results, or oral microbial amounts, and their results were included in the analyses. In addition, none suffered from oral cancer or an oral potentially malignant disorders (OPMD).

\section{Variables}

The primary outcomes were amounts of oral streptococci, oral fungi, and total bacteria, which were determined using a quantitative polymerase chain reaction (PCR) method. The outcome used to represent systemic frailty was nutritional condition assessed by BMI, with that calculated from measurements conducted at the institution using the following formula: weight $(\mathrm{kg}) /$ height $(\mathrm{cm})^{2}$. OHAT results were used for determination of oral frailty. To reveal relationships between those outcomes, information regarding potential confounders or effect modifiers, including gender, age, height, weight, application of special medical care, smoking and drinking habits, intake of antibacterial or anti-fungal medication, eating independence, and longterm care need level, was provided by the institution. This information was obtained from the facility care records, followed by confirmation with the caregiver in charge of each participant. Long-term care needs level is widely recognized in Japan as it is used in the national long-term care insurance system, which was established in 2000. Following receipt of an application from a community-dweller aged 65 years or older, their care needs level is determined by the applicable department for administration of their community based on examinations of mental and physical condition assessed by certification screening personnel, as well as a diagnosis from their primary physician. Long-term care needs consist of 7 levels, including support levels 1 and 2 , and care levels 1-5, aside from not applicable. Support level 1 represents the lowest level of care needed and care level 5 the highest [31]. For the present study, the range from support level 1 to care level 5 is referred to as long-term care needs level 1-7. Differences in dietary habits were not considered in this study, because the facility provides nearly the same food menu to all residents for each meal service.

Potential confounders or effect modifiers concerning oral health were assessed by oral examinations performed by two well-calibrated dentists, including present number of teeth, present tooth status, presence of oral cancer or OPMD, tongue moisture level, tongue coating deposits, and denture use frequency. Both examiners had received training in oral assessment for perioperative care of inpatients at Iwate Medical University Hospital prior to the study.

\section{Oral examinations}

Present tooth status including decayed and filled teeth was assessed according to the WHO criteria. Residual roots with or without coping treatment were recorded as a filled or decayed tooth, respectively. The presence of oral cancer or OPMD including leukoplakia, oral lichen planus, and erythroplakia, was determined using methods recommended by the WHO [32].

The moisture level of the tongue surface was measured using an intraoral moisture meter $\left(\right.$ Mucus $^{\circledR}$; Life, Saitama, Japan) at a point $1 \mathrm{~cm}$ posterior from the tip of the tongue along the median groove, as noted in a previous study [33]. Measurements were performed three times in each participant and the average value was used as the Mucus score. Tongue coating deposits were evaluated using tongue coating index (TCI). The surface of the tongue dorsum was divided into three sections vertically and three sections laterally (total nine sections). Each section was scored from 0 to 2 ( 0 : tongue coating not visible, 1: thin tongue coating, papillae of tongue visible, 2 : very thick tongue coating, papillae of tongue not visible) and the total score of the 9 sections was recorded as personal TCI [34]. Comprehensive oral health status was assessed using OHAT values, which is a validated tool used for assessment of oral health and comprises eight domains, including lips, tongue, gums and tissues, saliva, natural teeth, dentures, oral cleanliness, and dental pain, stratified into three grades (healthy, oral changes, unhealthy) [35]. In addition, at the oral examinations, denture use frequency was obtained by oral questioning of the participant or a caregiver. Denture use frequency 
was categorized into three levels; 1 : no use, 2: used for meals, and 3: always worn except at sleeping time.

\section{Collection and genome purification of microbial samples}

Microbial samples were collected immediately after the oral examination, as follows. The dorsum of the tongue was swabbed 20 times with a sterile cotton swab, which was then immersed in $1 \mathrm{ml}$ of sterile saline. Collected samples were transferred to the laboratory on ice and stored at $-80{ }^{\circ} \mathrm{C}$ until genome extraction. Genomic DNA was extracted and purified from the collected samples using a Wizard ${ }^{\circledR}$ Genomic DNA Purification Kit (Promega), according to the manufacturer's instructions. The microbial samples were lysed in $50 \mathrm{mM}$ EDTA, $1 \mathrm{mg} / \mathrm{ml}$ lysozyme (Thermo Fisher Scientific, Waltham, USA), $0.5 \mathrm{mg} / \mathrm{ml}$ lysostaphin (Fujifilm Wako Pure Chemical), and 1 unit/ml lyticase (Sigma-Aldrich, St. Louis, MO, USA) at $37{ }^{\circ} \mathrm{C}$ for $30 \mathrm{~min}$. In addition, samples were disturbed with an ISOFECAL for Beads Beating device (Nippon Gene, Tokyo, Japan) and a $\mu \mathrm{T}-12$ beads crusher (TAITEC, Saitama, Japan) at $3200 \mathrm{r} /$ minute for 5 min. Purified genomic DNA was dissolved in TE buffer (10 mM Tris-HCl, $1 \mathrm{mM}$ EDTA, pH 8.0) and stored at $-20^{\circ} \mathrm{C}$.

\section{Primer sets for polymerase chain reaction (PCR) assays}

A specific primer for amplifying the genome of oral streptococci was designed based on the S. mutans ATCC 25175 gene (NCBI Accession No. EF536028) and subjected to Primer-BLAST (basic local alignment search tool) (http://www.ncbi.nlm.nih.gov/tools/primer-blast/). The primer sequences $\left(5^{\prime}-3^{\prime}\right)$ targeting all streptococci elongation factor-Tu were CCAATGCCACAAACT CGTGAAC (forward) and GATCACGGATTTCCA TTTCAACC (reverse). To test the specificity of a streptococci-specific primer, the following strains were used: Streptococcus mutans ATCC 25175, S. sobrinus ATCC 27351, S. salivarius ATCC 7073, S. oralis ATCC 10557, S. gordonii ATCC 10558, S. sanguinis ATCC 10556, S. mitis ATCC 49456, S. constellatus ATCC 27823, S. anginosus NCTC10713, S. intermedius GAI 1157, S. pyogenes ATCC 12344, Enterococcus faecalis ATCC 29212, Staphylococcus aureus ATCC 25923, Staph. epidermidis ATCC 14990, Fusobacterium nucleatum ATCC 25586, and Escherichia coli BL21. They were cultured in trypticase soy broth (TSB, Becton Dickinson, Sparks, MD, USA) under an anaerobic condition $\left(80 \% \mathrm{~N}_{2}, 10 \% \mathrm{CO}_{2}, 10 \%\right.$ $\mathrm{H}_{2}$ ) at $37^{\circ} \mathrm{C}[36,37]$.

One ng of each bacterial DNA sample was confirmed by detection with the streptococci specific primer set using KOD-Plus-Neo DNA polymerase (TOYOBO, Tokyo, Japan). The amplification cycles were as follows: 2 min at $98{ }^{\circ} \mathrm{C}$ for initial heat activation, then one cycle for $10 \mathrm{~s}$ at $94{ }^{\circ} \mathrm{C}, 10 \mathrm{~s}$ at $62{ }^{\circ} \mathrm{C}$, and $5 \mathrm{~s}$ at $68{ }^{\circ} \mathrm{C}$, for a total of 30 cycles. These PCR products were subjected to agarose gel electrophoresis using a 3.0\% gel and stained with ethidium bromide, with detection performed at $302 \mathrm{~nm}$ with ChemiDoc XRS Plus (Bio-Rad Laboratories, Hercules, CA, USA). DNA amplicons were observed in ten oral streptococci, while no PCR products were demonstrated with DNA samples from the other six bacteria species (Additional file 1). For amplifying the genome of bacterial 16S rRNA universal and eukaryotic 18S rRNA genes, primer sets reported in previous studies were used $[38,39]$. The primer sequences $\left(5^{\prime}-3^{\prime}\right)$ targeting bacterial the 16S rRNA gene were CGCTAGTAATCGTGGATC AGAATG (forward) and TGTGACGGGCGGTGTGTA (reverse), and those $\left(5^{\prime}-3^{\prime}\right)$ targeting the $18 \mathrm{~S}$ rRNA gene were TCTCAGGCTCCYTCTCCGG (forward) and AAG CCATGCATGYCTAAGTATMA (reverse).

\section{Determination of microbial amounts}

Stored samples were solved in room temperature. From those samples, genomic DNA was extracted and purified by the same method used for reference microorganisms. To determine microbial amounts in each sample, quantitative PCR assays were performed using a Thermal Cycler Dice Real-Time System II and with the following thermal cycle, as recommended for the TB Green Ex Taq (Takara Bio, Kusatsu, Japan) mixture: $95^{\circ} \mathrm{C}$ for $30 \mathrm{~s}$, then 40 cycles for $5 \mathrm{~s}$ at $95^{\circ} \mathrm{C}$ and $1 \mathrm{~m}$ at $58^{\circ} \mathrm{C}$ for $16 \mathrm{~S}$ rRNA and $18 \mathrm{~S}$ rRNA, and at $62{ }^{\circ} \mathrm{C}$ for oral streptococcal EF-Tu. Ten ng of genomic DNA from the samples was used as the template. Standard curves for each organism were plotted using $C t$ values obtained from amplification of genomic DNA. Those were extracted from $S$. salivarius ATCC $7073\left(1.0 \times 10^{2}\right.$ to $\left.1.0 \times 10^{6} \mathrm{CFU}\right)$ and $C$. albicans SC $5314\left(1.0 \times 10^{1}\right.$ to $\left.1.0 \times 10^{6} \mathrm{CFU}\right)$ cells. The numbers of S. salivarius and C. albicans were determined by plating culture dilutions in trypticase soy agar and YPD agar plates, respectively $[38,40]$. The linearity of these assays was correlated between the $C t$ and microbial amounts. Correlation coefficients were 0.969 for $16 \mathrm{~S}$ rRNA, 0.985 for oral streptococcal EF-Tu, and 0.979 for 18S rRNA. The amounts of the microorganisms are expressed as logarithm number of CFU.

\section{Statistical analysis}

Age, BMI, care needs score, number of teeth, TCI, Mucus score, OHAT score, and amounts of oral microorganisms were used as continuous variables. After distributions of all continuous variables were tested by one-sample Kolmogorov-Smirnov test, variables with normal distribution (age, BMI, total bacterial amount, streptococcal amount) were used as quantitative variables. Variables that did not show a normal distribution treated as rank 
variables. Gender, need for special medical care, edentulous status, and denture wearer were treated as categorical variables.

For assessing nutritional condition, the participants were classified as $\mathrm{BMI}<20$ (undernutrition) or $\geq 20$ (not undernutrition), according to the criteria for Asian elder people aged 70 years or older in The Global Leadership Initiative on Malnutrition (GLIM) [41]. For OHAT, the participants were divided into low (score $\leq 5)$ and high (score $>5$ ) OHAT groups, after referring to the median of the participants in this study and a cut-off value in previous study [42]. For comparison tests between the groups, Mann-Whitney's U test was used for rank variables and Fisher's exact test for categorical variables. Single correlations for combinations of quantitative variables were tested using Pearson's correlation coefficient analysis, while Spearman's rank correlation analysis was used for combinations of rank or categorical variables after the categorical variables were transformed into binary variables. Eating independence was entered as a three-level rank variable in Spearman's rank correlation analysis and as a categorical variable in the following comparisons between groups.

For multivariable analysis to elucidate factors related with BMI or OHAT, multiple logistic regression analyses were performed. In the model for BMI, the dependent variable was set as "not undernutrition" $(\mathrm{BMI} \geq 20: 1, \mathrm{BMI}<20: 0)$ and three variables (streptococcal amount, eating independence level, TCI) were selected as independent variables based on the results of the single correlation analysis. For OHAT, a regression model was constructed using high OHAT as the dependent variable $(\mathrm{OHAT} \geq 5: 1, \mathrm{OHAT}<5: 0)$ to determine the amount indicating poor oral health condition. For confounding factors, number of decayed teeth and eating independence were excluded from the regression models, since those are included in the OHAT criteria or were evaluated as part of determination of long-term care need. As a result, long-term care need level, denture use frequency, and fungal amount were used as independent variables. SPSS for Windows software, ver. 25.0 (IBM SPSS, Tokyo, Japan), was used for all data analyses.

This study followed the STROBE statement for reports of observational studies (Additional file 2).

\section{Results}

Comparisons of health conditions and microbial amounts between participants with and without undernutrition Fifteen of the 41 participants were determined to have undernutrition based on a BMI cut-off value of $<20$, with the average $\pm S D$ for those $17.5 \pm 1.43$, while that was $23.5 \pm 3.49$ for the participants in the group without undernutrition. Other than BMI, there were no significant differences between the groups for other systemic or oral health conditions (Table 1). As for microbial measurements, only streptococcal amounts showed a statistically significant difference between groups with and without undernutrition, with the average $\pm S D$ values for streptococcal amount as the

Table 1 Comparisons of health conditions and microbial amounts between participants with undernutrition and adequate nutrition

\begin{tabular}{|c|c|c|c|c|}
\hline & $\begin{array}{l}\text { With undernutrition } \\
(\mathrm{BMI} \geq 20, \mathrm{n}=15)\end{array}$ & $\begin{array}{l}\text { Adequate nutrition } \\
(\mathrm{BMI}<20, \mathrm{n}=26)\end{array}$ & Total & $\begin{array}{l}p \text { value in } \\
\text { comparison } \\
\text { test }\end{array}$ \\
\hline $\mathrm{BMI}$ & $17.5 \pm 1.43$ & $23.5 \pm 3.49$ & $21.3 \pm 4.10$ & $<0.001^{\mathrm{a}}$ \\
\hline Males/females, \% & $4 / 11,26.7$ & $4 / 22,15.4$ & $8 / 33,19.5$ & $0.434^{b}$ \\
\hline Age in years (average \pm SD) & $85.7 \pm 9.70$ & $83.9 \pm 7.47$ & $84.6 \pm 8.28$ & $0.523^{a}$ \\
\hline Care needs score (median, range) & $6,1-7$ & $5,1-7$ & $5,1-7$ & $0.445^{c}$ \\
\hline Eating independence (not independent/independent, \%) & $6 / 9,40.0$ & $7 / 19,26.9$ & $13 / 28,31.7$ & $0.492^{b}$ \\
\hline Mucus score (median, range) & $24.3,0.2-28.1$ & $25.7,1.5-29.9$ & $25.3,0.2-29.9$ & $0.315^{c}$ \\
\hline TCI score (median, range) & $1,1-9$ & $2,1-13$ & $2.0,1-13$ & $0.173^{c}$ \\
\hline Number of present teeth (median, range) & $4,0-26$ & $8.5,0-25$ & $6,0-26$ & $0.341^{c}$ \\
\hline Number of decayed teeth (median, range) & $0,0-4$ & $0,0-9$ & $0,0-9$ & $0.659^{c}$ \\
\hline Number of filled teeth (median, range) & $2,0-16$ & $6,0-21$ & $3,0-21$ & $0.108^{c}$ \\
\hline Edentulous subjects (edentulous/dentate, \%) & $6 / 9,40.0$ & $5 / 21,19.2$ & $11 / 30,26.8$ & $0.272^{b}$ \\
\hline Denture wearers (wearers/non-wearers, \%) & $8 / 7,53.3$ & $16 / 10,61.5$ & 23/18, 56.1 & $0.515^{b}$ \\
\hline OHAT score (median, range) & $5,1-13$ & $5,1-10$ & $5,1-13$ & $0.512^{c}$ \\
\hline
\end{tabular}

a t test

${ }^{\mathrm{b}}$ Fisher's exact test

'Mann-Whitney U test 


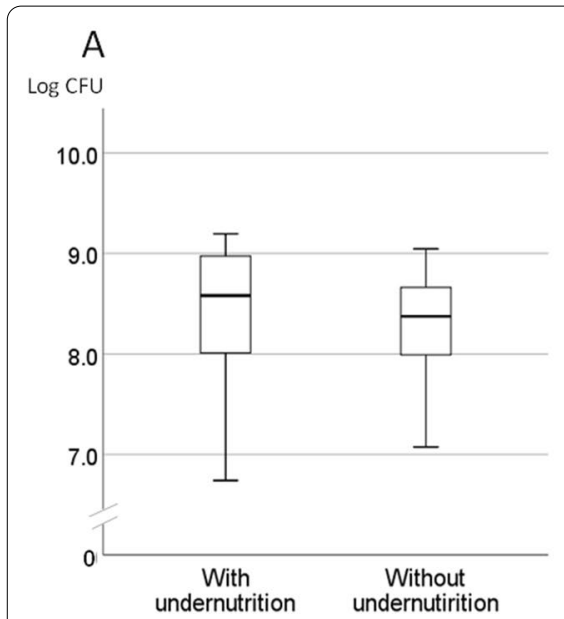

\section{B}

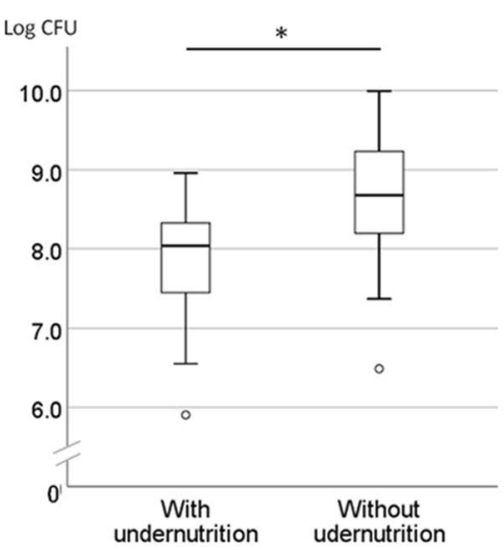

C

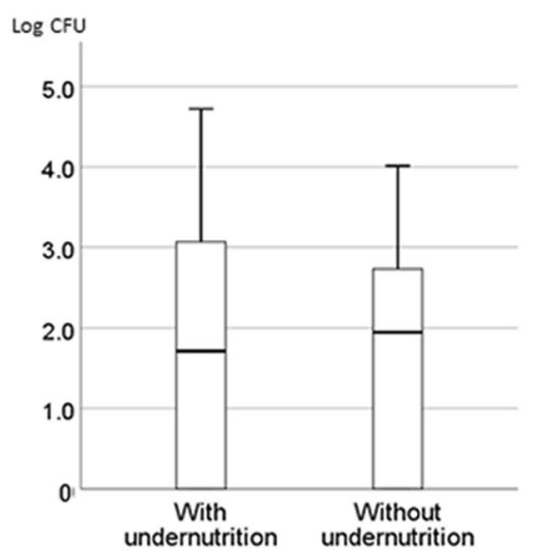

Fig. 2 Comparisons of microbial amounts between groups with and without undernutrition. A Total bacteria. B Streptococci. C. Fungi. The bold line in the middle of the box indicates the median. The bottom edge of the box shows the 25th percentile and the top edge the 75 th percentile. Whiskers at the bottom and top of the box indicate minimum and maximum values, respectively. Circle below the whisker indicates an outlier. ${ }^{*} p=0.003$, t test

logarithm number of CFU $7.80 \pm 0.86$ and $8.76 \pm 0.83$ respectively (Fig. 2).

\section{Comparisons of health conditions and microbial amounts between participants with and without poor oral health condition}

Twenty-six of the 41 participants had a high OHAT score $(>5)$, indicating a poor oral health condition, with the median and range for the high OHAT group 6 and
5-13, respectively, and for the low OHAT group, 2 and $1-4$, respectively. As for systemic and oral health conditions, significant differences were found between the groups for care needs score, rate of participants with eating independence, and number of decayed teeth (Table 2). In microbial analyses, fungal amount was significantly higher in the high OHAT group participants with poor oral health, with median and range values of 2.45 and $0-4.72$, respectively, for the group with poor

Table 2 Comparisons of health conditions and microbial amounts between participants with and without poor oral health condition

\begin{tabular}{|c|c|c|c|c|}
\hline & $\begin{array}{l}\text { With poor oral health } \\
\text { (OHAT } \geq 5, n=26)\end{array}$ & $\begin{array}{l}\text { Without poor oral } \\
\text { health }(\mathrm{OHAT}<5, \mathrm{n}=15)\end{array}$ & Total $^{\mathrm{d}}$ & $\begin{array}{l}p \text { value in } \\
\text { comparison } \\
\text { test }\end{array}$ \\
\hline OHAT score (median, range) & $6,5-13$ & $2,1-4$ & $5,1-13$ & $<0.001^{c}$ \\
\hline Males/females, \% & $4 / 22,15.4$ & $4 / 11,26.7$ & $8 / 33,19.5$ & $0.434^{b}$ \\
\hline Age in years (average $\pm S D$ ) & $85.9 \pm 8.49$ & $82.3 \pm 7.62$ & $84.6 \pm 8.28$ & $0.181^{\mathrm{a}}$ \\
\hline BMI & $21.2 \pm 4.65$ & $21.5 \pm 3.04$ & $21.3 \pm 4.10$ & $0.812^{\mathrm{a}}$ \\
\hline Care needs score (median, range) & $6,2-7$ & $1,1-6$ & $5,1-7$ & $<0.001^{c}$ \\
\hline Eating independence (not independent/independent, \%) & $13 / 13,50.0$ & $0 / 15,0.0$ & $13 / 28,46.4$ & $0.001^{b}$ \\
\hline Mucus score (median, range) & $24.1,0.2-29.9$ & $26.5,18.8-29.9$ & $25.3,0.2-29.9$ & $0.181^{c}$ \\
\hline $\mathrm{TCl}$ socre (median, range) & $2,1-13$ & $2,1-9$ & $2.0,1-13$ & $0.825^{c}$ \\
\hline Number of present teeth (median, range) & $7,0-26$ & $2,0-23$ & $6,0-26$ & $0.583^{c}$ \\
\hline Number of decayed teeth (median, range) & $0,0-9$ & $0,0-1$ & $0,0-9$ & $0.030^{c}$ \\
\hline Number of filled teeth (median, range) & $4.5,0-19$ & $2,0-21$ & $3,0-21$ & $0.947^{c}$ \\
\hline Edentulous subjects (edentulous/dentate, \%) & $5 / 21,23.8$ & $6 / 9,40.0$ & $11 / 30,73.2$ & $0.272^{b}$ \\
\hline Denture wearer (wearers/non-wearers, \%) & $12 / 14,46.2$ & $11 / 4,73.3$ & $23 / 18,56.1$ & $0.114^{b}$ \\
\hline
\end{tabular}

at test

${ }^{\mathrm{b}}$ Fisher's exact test

'Mann-Whitney U test

d Same data as shown in Table 1 excluding OHAT 


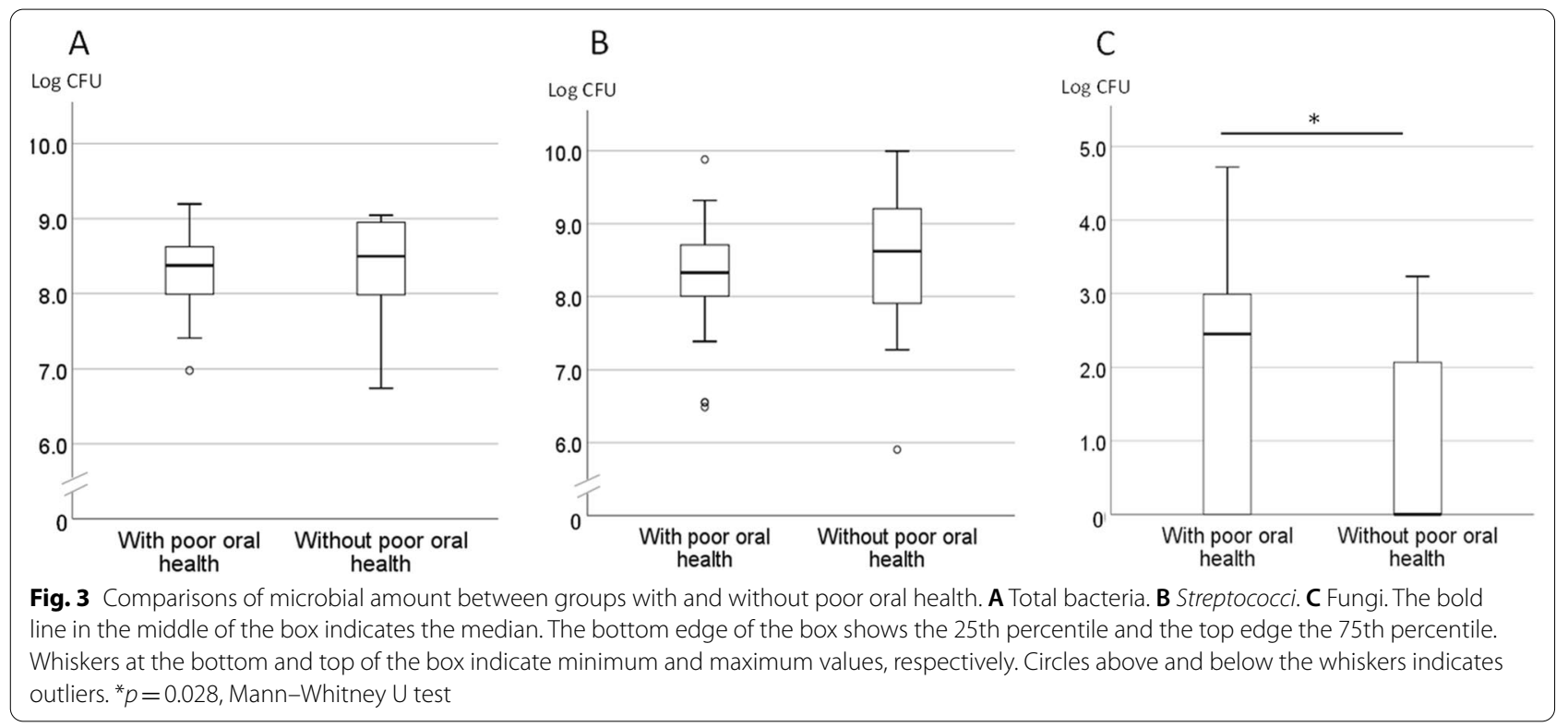

oral health, and 0 and $0-3.32$, respectively, for the group without poor oral health. No association with OHAT score was found for total bacterial amount or streptococcal amount (Fig. 3).

\section{Measurements related with microbial amounts}

The association between each microbial amount and other observed values was assessed by single correlation coefficient analysis. Table 3 shows correlation coefficients of significantly related measurements with the amount of any microorganism in addition to OHAT score. In the examination of correlations between microbial amounts,

Table 3 Correlations among microbial amounts, and nutritional and oral conditions

\begin{tabular}{|c|c|c|c|c|c|c|c|c|}
\hline & $\begin{array}{l}\text { Total } \\
\text { bacterial } \\
\text { amount }\end{array}$ & $\begin{array}{l}\text { Streptococc-al } \\
\text { amount }\end{array}$ & Fungal amount & BMI & $\begin{array}{l}\text { Eating } \\
\text { independence }^{b}\end{array}$ & $\mathrm{TCl}$ & Mucus score & OHAT score \\
\hline \multirow[t]{2}{*}{ Total bacterial amount } & 1.00 & $0.593^{\mathrm{a}}$ & -0.205 & $-0.104^{\mathrm{a}}$ & 0.150 & 0.346 & -0.011 & 0.073 \\
\hline & & $<0.001$ & 0.199 & 0.516 & 0.348 & 0.029 & 0.949 & 0.651 \\
\hline \multirow[t]{2}{*}{ Streptococcal amount } & $0.593^{\mathrm{a}}$ & 1.00 & -0.141 & $0.420^{\mathrm{a}}$ & -0.290 & -0.053 & 0.075 & -0.171 \\
\hline & $<0.001$ & & 0.379 & 0.006 & 0.066 & 0.746 & 0.654 & 0.286 \\
\hline \multirow[t]{2}{*}{ Fungal amount } & -0.205 & -0.141 & 1.00 & -0.055 & 0.228 & -0.331 & -0.383 & 0.287 \\
\hline & 0.199 & 0.379 & & 0.732 & 0.152 & 0.037 & 0.018 & 0.068 \\
\hline \multirow[t]{2}{*}{ BMI } & $-0.104^{\mathrm{a}}$ & $0.420^{\mathrm{a}}$ & -0.055 & 1.00 & -0.269 & -0.244 & 0.017 & -0.184 \\
\hline & 0.516 & 0.006 & 0.732 & & 0.089 & 0.130 & 0.921 & 0.250 \\
\hline \multirow[t]{2}{*}{ Eating independence } & 0.150 & -0.290 & 0.228 & -0.269 & 1.00 & 0.169 & -0.157 & 0.565 \\
\hline & 0.348 & 0.066 & 0.152 & 0.089 & & 0.297 & 0.346 & $-<0.001$ \\
\hline \multirow[t]{2}{*}{$\mathrm{TCl}$} & 0.346 & -0.053 & -0.331 & -0.244 & 0.169 & 1.00 & 0.091 & 0.010 \\
\hline & 0.029 & 0.746 & 0.037 & 0.130 & 0.297 & & 0.585 & 0.952 \\
\hline \multirow[t]{2}{*}{ Mucus score } & -0.011 & 0.075 & -0.383 & 0.017 & -0.157 & 0.091 & 1.00 & -0.191 \\
\hline & 0.949 & 0.654 & 0.018 & 0.921 & 0.346 & 0.585 & & 0.250 \\
\hline \multirow[t]{2}{*}{ OHAT score } & 0.073 & -0.171 & 0.287 & -0.184 & 0.565 & 0.010 & -0.191 & 1.00 \\
\hline & 0.651 & 0.286 & 0.068 & 0.250 & $<0.001$ & 0.952 & 0.250 & \\
\hline
\end{tabular}

Values significantly related with amount of microorganisms and OHAT are shown

Upper value shows correlation coefficient and lower value $p$ value

a Pearson's correlation coefficient. The other correlation coefficient was determined as Spearman's rank correlation coefficient

${ }^{b}$ Degree of eating independence was scored as follows: 1, independent; 2, partial assistance needed; 3, full assistance needed 


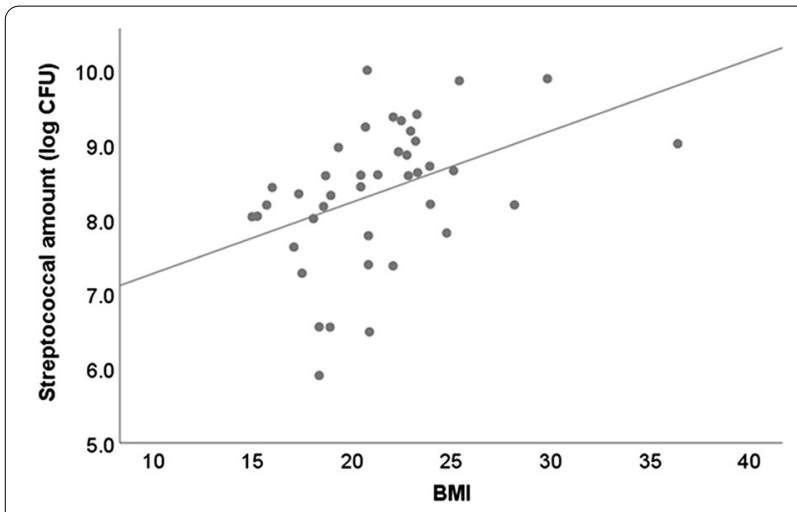

Fig. 4 Scatter plot showing correlation between streptococcal amount and BMI. Straight line indicates regression $(r=0.420)$

there was a significant positive relationship between total bacterial and streptococcal amounts $(\mathrm{r}=0.593, p<0.001)$. On the other hand, fungi showed a negative relationship with both total bacteria and streptococci, though that was slight and not significant. For nutritional condition, only streptococcal amount showed a significant correlation with BMI $(r=0.420, p=0.006)$. Linear correlations are shown in Fig. 4. TCI was positively related with total bacterial amount $(\rho=0.346, p=0.029)$ and negatively related with fungal amount $(\rho=-0.331, p=0.037)$. Moreover, fungal amount showed a significant negative correlation with Mucus score $(\rho=-0.383, p=0.018)$. OHAT score did not have a significant relationship with fungal amount $(\rho=-0.287, p=0.068)$.

\section{Multiple logistic regression analyses}

In the full model with "not undernutrition" as the dependent variable, streptococcal amount was the only significant variable, with an adjusted odds ratio (AOR) of 6.10 $(p=0.006)$. After a stepwise procedure, streptococcal amount was selected for the final model (Table 4). As a

Table 4 Logistic regression models for poor oral health condition

\begin{tabular}{|c|c|c|c|c|}
\hline & Variable & AOR & $95 \% \mathrm{Cl}$ & $p$ value \\
\hline \multirow[t]{3}{*}{ Full enter model } & $\begin{array}{l}\text { Long-term care need } \\
\text { level }\end{array}$ & 2.60 & $1.40-4.82$ & 0.002 \\
\hline & Fungal amount & 2.72 & $1.05-7.05$ & 0.039 \\
\hline & $\begin{array}{l}\text { Denture use fre- } \\
\text { quency }\end{array}$ & 0.386 & $0.107-1.40$ & 0.147 \\
\hline \multirow{2}{*}{$\begin{array}{l}\text { Final model after } \\
\text { stepwise proce- } \\
\text { dure }\end{array}$} & $\begin{array}{l}\text { Long-term care need } \\
\text { level }\end{array}$ & 2.60 & $1.52-5.13$ & 0.002 \\
\hline & Fungal amount & 2.44 & $0.987-6.04$ & 0.053 \\
\hline
\end{tabular}

Dependent variable: OHAT > 5: 1, OHAT $\leq 5: 0$

AOR, adjusted odds ratio; $\mathrm{Cl}$, confidential interval
Table 5 Logistic regression models for adequate nutrition

\begin{tabular}{llccc}
\hline & Variable & AOR & $\mathbf{9 5 \%} \mathrm{Cl}$ & $\boldsymbol{p}$ value \\
\hline Full enter model & $\begin{array}{l}\text { Streptococcal } \\
\text { amount }\end{array}$ & 6.10 & $1.66-22.4$ & 0.006 \\
& TCl & 0.816 & $0.620-1.07$ & 0.146 \\
& $\begin{array}{l}\text { Eating independence } \\
\text { Final model after }\end{array}$ & 0.744 & $0.264-2.10$ & 0.577 \\
$\begin{array}{l}\text { Streptococcal } \\
\text { dure }\end{array}$ & 6.32 & $1.71-23.3$ & 0.006 \\
& amount & & & \\
\hline
\end{tabular}

Dependent variable: $\mathrm{BMI} \geq 20: 1, \mathrm{BMI}<20: 0$

$A O R$, adjusted odds ratio; $\mathrm{Cl}$, confidential interval

result, the adjusted odds ratio (AOR) was 6.32, with a $95 \%$ confidential interval (CI) of 1.71-23.3 ( $p=0.006)$ (Table 5).

In multiple regression analyses related to high OHAT (poor oral health condition), long term care need level and fungal amount were shown to be significant variables in the full enter model (AOR: 2.60 and 2.72, $p=0.002$ and 0.39 , respectively). After a stepwise procedure, long-term care need level and fungal amount were selected for the final model (Table 6). For fungal amount, the AOR was 2.44 , with a $95 \% \mathrm{CI}$ of $0.987-6.04(p=0.053)$.

\section{Discussion}

Among the elders participated in this study, the amount of oral streptococci was found to be significantly lower in the undernutrition group $(7.80 \pm 0.86$ vs. $8.67 \pm 0.83)$, while a significant association $(r=0.420)$ between amount of streptococci and BMI was found in the entire participants. Furthermore, using a multiple logistic regression model in which "not malnutrition" was the dependent variable, the amount of oral streptococci was selected as a significant independent variable with high AOR (6.32) in the final model after a stepwise procedure. BMI, which is widely used to determine whether an individual is under- or overweight, and also employed in a variety of nutrition assessment tools as a criterion for assessing undernutrition [41, 43, 44], was used in this study as an indicator of systemic nutritional condition. The average BMI value for the present participants was 21.3 , within the average range (20.6-22.5) reported in previous investigations conducted in Japan of institutionalized older individuals [45-47]. Thus, their nutritional status was considered to be comparable to that of institutionalized elderly in Japan.

Bacteria belonging to the genus Streptococcus are the initial inhabitants of the oral cavity, as they are generally acquired right after birth and play an important role in assembly of the oral microbiota [14]. Moreover, dominance continues until old age [48]. Most oral streptococci 
are not pathogenic and thought to contribute to oral homeostasis [14], though a change in eating conditions could have an influence on the normal Streptococcusdominant balance of the oral microbiota. Takeshita et al. reported that dominant genera such as Streptococcus were observed in much lower proportions in tube-fed subjects as compared to those fed orally [49]. Even when an oral-environmental change is not as drastic as tube feeding, a decrease in food intake could have a negative effect on growth of oral streptococci, since eating by mouth supplies nutrition to microbes necessary for maintenance of the indigenous oral microbiota. Staple foods in most human populations include starch rich crops such as rice, wheat, and potatoes. Polysaccharides composing starch are degraded by cooking with heat and salivary amylase into mono- or disaccharides, which are easily metabolized by oral streptococci $[14,50,51]$. A decrease in the amount of food intake via the oral cavity restricts the energy source for streptococcal organisms as well as the human host. Such restriction results in energy source reduction as well as aging-related changes in the oral cavity, represented by decreased saliva flow and an altered oral immune system [52]. Saliva contains secretory IgAs and anti-microbial peptides. However, commensal oral streptococci, such as S. mitis, S. oralis, and S. sanguinis, have become adapted to those components [53-55]. Thus, a decrease in saliva may cause Streptococcus to fail to dominate the oral cavity, consequently allowing easier grow for other microorganisms.

On the other hand, fungal amount is related with oral moisture condition and oral health. Wu et al. reported that oral care intervention in patients with end stage of cancer reduced detection of Candida on the tongue, accompanied by a decrease in OHAT score [56], which was confirmed by the present results. OHAT criteria for assessments of lip, tongue, gum tissues, and saliva include dryness, with oral dryness one of the significant factors related to fungal colonization in the oral cavity $[57,58]$. Saliva contains glycoproteins, which act to inhibit adhesion of fungi to epithelial cells [59], and also antimicrobial proteins, histatins, defensins, and other components that can suppress Candida spp. [60]. Thus, a dry condition is preferable for fungi colonization. In contrast to streptococci, fungi have an ability to grow under altered mucosal conditions. Such differences in suitable conditions for colonization may allow fungi and streptococci to grow competitively in the oral cavity. However, previous in vitro studies of the relationship between fungal and streptococcal colonization have shown contradictory results. Some demonstrated that oral streptococci contribute to colonization of oral fungi or modification of their virulence $[61,62]$, while others have reported that a specific streptococcus could inhibit Candida colonization in the oral cavity [63-65]. In the present study, both fungal and streptococcal amounts in the oral cavities of the same subjects were determined, and the results showed a negative, though not significant, relationship between oral streptococcal and fungal abundance. The actual balance of fungi and streptococcus colonization in the human oral cavity is unknown, and the present results as well did not show an obvious relationship. Elucidation of the prevalence of both oral fungi and indigenous streptococci in the oral cavity is important for understanding the relationship between frailty and oral health in elderly individuals. It is considered that the oral streptococcus-specific primer established in the present study will be an effective tool for future surveys.

This study has some limitations. First, it is difficult to generalize the results due to the small number of participants residing at a single institution. Also, direct assessments of symptoms of frailty and amount of food intake were not performed, thus the actual relationships of oral microbiota with frailty or food intake amount were not clearly elucidated. Furthermore, because of the cross-sectional design, changes in BMI were not recorded, though it is known that a rapid decrease in $\mathrm{BMI}$ is as important as a stable state for assessment of frailty in elders [37]. Additionally, some potential biases are assumed. For example, this study showed that OHAT values were lower and oral health better in participants who were able to eat independently. However, dietary management for elder individuals by a caregiver may result in stabilization of food intake and help the individual maintain a better BMI as compared to those who eat independently based on their own preferences. Thus, additional studies with greater numbers of subjects and multiple institutions that utilize longitudinal observations are required.

Based on the results of this study, in order to prevent progression of frailty in elder individuals, greater consumption of foods with moisturizing effects may be effective to maintain a balance of streptococci and fungi that results in a streptococcus-dominant state. In the future, it will be desirable to develop probiotic foods that inhibit fungi and promote streptococcal growth. As an indicator of the effects of such interventions, simultaneous evaluation of streptococcus and fungus amounts is useful.

\section{Conclusion}

Oral streptococcal levels were found to be associated with the general nutritional status of institutionalized older individuals, while oral fungal levels were associated 
with oral health status. Therefore, it is necessary to survey both oral indigenous streptococci as well as fungi to understand the relationship of frailty with oral microbiota, as well as assess the effects of intervention on the oral health of elderly individuals.

\section{Abbreviations}

AOR: Adjusted odds ratio; BMI: Body Mass Index; CFU: Colony forming units/ $\mathrm{mL}$; Cl: Confidential interval; OHAT: Oral health assessment tool; SD: Standard deviation; TCl: Tongue Coating Index; WHO: World Health Organization.

\section{Supplementary Information}

The online version contains supplementary material available at https://doi. org/10.1186/s12903-021-01926-0.

Additional file 1. PCR products from 16 strains of streptococcus specific primer designed for this study.

Additional file 2. Strobe check list.

\section{Acknowledgements}

We would like to express our deep gratitude to the staff members of the Long-Term Care Health Institution as well as Mr. Katsufumi Miyasaka, chairman of the social welfare corporation Sapporo Keiyukai, for their cooperation in this clinical study. A research grant from Iwate Prefecture for Strategic Developmental Research was provided as support for this investigation.

\section{Authors' contributions}

HS was in charge of the sample collection, oral examinations, and microbiological analyses, including sample preparations, genome purification, and polymerase chain reaction analyses of all reference microorganisms and oral specimens, as well as writing the manuscript. AY contributed to the study concept and was in charge of planning the microbial analyses, in addition to liaison and coordination with cooperating institution, and helping draft the manuscript. YS conducted microbiological analyses including design of the PRC primer and also determined the optimal conditions for detection of microorganisms in the oral specimens. TS contributed to collection of oral specimens. YS was involved with collection of oral specimens and oral examinations. MK contributed to the study concept, and was in charge of data collection and statistical analyses, and also responsible for writing the manuscript. All authors read and approved the final manuscript.

\section{Funding}

A research grant from Iwate Prefecture for Strategic Developmental Research was received for this study.

\section{Availability of data and materials}

The primer sequences targeting all streptococci created for this study have not been uploaded. Datasets used and/or analyzed in this study are available from the corresponding author upon reasonable request.

\section{Declarations}

\section{Ethics approval and consent to participate}

Informed consent was obtained from all participants who took part in this study. The study protocol was approved by the Medical Ethics Committee of Iwate Medical University School of Dentistry (01340).

\section{Consent for publication}

Not applicable.

\section{Competing interests}

The authors have no conflicts of interest to declare.

\section{Author details}

${ }^{1}$ Division of Preventive Dentistry, Department of Oral Medicine, Iwate Medical University School of Dentistry, 1-3-27 Chuo-dori, Morioka, Iwate 020-8505, Japan. ${ }^{2}$ Iwate Biotechnology Research Center, 174-4 Narita 22 Jiwari, Kitakami, Iwate 024-0003, Japan. ${ }^{3}$ Division of Molecular Microbiology, Department of Microbiology, Iwate Medical University, 1-1 Idai Dori 1 chome, Yahaba, Iwate 028-3694, Japan.

Received: 30 Auqust 2021 Accepted: 22 October 2021

Published online: 19 November 2021

\section{References}

1. Fried $L P$, Tangen $C M$, Walston J, et al. Cardiovascular health study collaborative research group: frailty in older adults: evidence for a phenotype. J Gerontol A Biol Sci Med Sci. 2001;56(3):146-56.

2. Graham JE, Snih SA, Berges IM, Ray LA, Markides KS, Ottenbacher KJ. Frailty and 10-year mortality in community-living Mexican American older adults. Gerontology. 2009;55(6):644-51.

3. Ensrud KE, Ewing SK, Cawthon PM, et al. Osteoporotic Fractures in Men Research Group: a comparison of frailty indexes for the prediction of falls, disability, fractures, and mortality in older men. J Am Geriatr Soc. 2009:57(3):492-8.

4. Alves S, Teixeira L, Ribeiro O, Paúl C. Examining frailty phenotype dimensions in the oldest old. Front Psychol. 2020;11:434. https://doi.org/10. 3389/fpsyg.00434.

5. Lewis EG, Coles S, Howorth K, Kissima J, Gray W, Urasa S, Walker R, Dotchin $C$. The prevalence and characteristics of frailty by frailty phenotype in rural Tanzania. BMC Geriatr. 2018;18(1):283. https://doi.org/10.1186/ s12877-018-0967-0.

6. Dibello V, Zupo R, Sardone R, Lozupone M, Castellana F, Dibello A, Daniele A, De Pergola G, Bortone I, Lampignano L, Giannelli G, Panza F. Oral frailty and its determinants in older age: a systematic review. Lancet Healthy Longev. 2021;2:e507-20.

7. Lamy M, Mojon P, Kalykakis G, Legrand R, Butz-Jorgensen E. Oral status and nutrition in the institutionalized elderly. J Dent. 1999;27(6):443-8.

8. Wu LL, Cheung KY, Lam PYP, Gao XL. Oral health indicators for risk of malnutrition in elders. J Nutr Health Aging. 2018;22(2):254-61.

9. Zelig R, Goldstein S, Touger-Decker R, Firestone E, Golden A, Johnson Z, Kaseta A, Sackey J, Tomesko J, Parrott JS. Tooth loss and nutritional status in older adults: a systematic review and meta-analysis. JDR Clin Trans Res. 2020;21:2380084420981016. https://doi.org/10.1177/2380084420981016.

10. Sura L, Madhavan A, Carnaby G, Crary MA. Dysphagia in the elderly: management and nutritional considerations. Clin Interv Aging. 2012;7:287-98.

11. Katagiri S, Shiba T, Tohara H, Yamaguchi K, Hara K, Nakagawa K, Komatsu K, Watanabe K, Ohsugi Y, Maekawa S, Iwata T. Re-initiation of oral food intake following enteral nutrition alters oral and gut microbiota communities. Front Cell Infect Microbiol. 2019;9:434. https://doi.org/10.3389/fcimb.2019.00434.

12. Yamashita Y, Takeshita T. The oral mirobiome and human health. J Oral Sci. 2017:59(2):201-6.

13. Gao L, XuT, Huang G, Jiang S, Gu Y, Chen F. Oral microbiomes: more and more importance in oral cavity and whole body. Protein Cell. 2018;9(5):488-500.

14. Abranches J, Zeng L, Kajfasz JK, Palmer SR, Chakraborty B, Wen T, Richards VP, Brady LJ, Lemos JA. Biology of oral streptococci. Microbiol Spectr. 2018;6(5):10. https://doi.org/10.1128/microbiolspec.GPP3-0042-2018.

15. Tada A, Senpuku H, Motozawa Y, Yoshihara A, Hanada N, Tanzawa H. Association between commensal bacteria and opportunistic pathogens in the dental plaque of elderly individuals. Clin Microbiol Infect. 2006;12(8):776-81.

16. Ulloa PC, van der Veen MH, Krom BP. Review: modulation of the oral microbiome by the host to promote ecological balance. Odontology. 2019;107(4):437-48.

17. Sampaio-Maia B, Caldas IM, Pereira ML, Pérez-Mongiovi D, Araujo R. The oral microbiome in health and its implication in oral and systemic diseases. Adv Appl Microbiol. 2016;97:171-210. 
18. Kishi M, Ohara-Nemoto Y, Takahashi M, Kishi K, Kimura S, Yonemitsu M. Relationship between oral status and prevalence of peridontopathic bacteria on the tongues of elderly individuals. J Med Microbiol. 2010;59(Pt 11):1354-9.

19. Gould IM, MacKenzie FM. Antibiotic exposure as a risk factor for emergence of resistance: the influence of concentration. Symp Ser Soc Appl Microbiol. 2002;31:78S-84S.

20. Narhi TO, Ainamo A, Meurman JH. Salivary yeasts, saliva, and oral mucosa in the elderly. J Dent Res. 1993;72(6):1009-14.

21. de Resende MA, de Sousa LV, de Oliveira RC, Koga-Ito CY, Lyon JP. Prevalence and antifungal susceptibility of yeasts obtained from the oral cavity of elderly individuals. Mycopathologia. 2006;162(1):39-44.

22. Sato T, Kishi M, Suda M, Sakata K, Shimoda H, Miura H, Ogawa A, Kobayashi S. Prevalence of Candida albicans and non-albicans on the tongue dorsa of elderly people living in a post-disaster area: a crosssectional survey. BMC Oral Health. 2017;17(1):51. https://doi.org/10.1186/ s12903-017-0342-0.

23. Scully C, El-Kabir M, Samaranayake LP. Candida and oral candidosis: a review. Crit Rev Oral Biol Med. 1994;5(2):125-57.

24. Sharon V, Fazel N. Oral candidiasis and angular cheilitis. Dermatol Ther. 2010;23(3):230-42. https://doi.org/10.1111/j.1529-8019.2010.01320.x.

25. Paillaud E, Merlier I, Dupeyron C, Scherman E, Poupon J, Bories PN. Oral candidiasis and nutritional deficiencies in elderly hospitalised patients. $\mathrm{Br} J$ Nutr. 2004;92(5):861-7.

26. Zakaria MN, Furuta M, Takeshita T, Shibata Y, Sundari R, Eshima N, Ninomiya T, Tamashita Y. Oral mycobiome in community-dwelling elderly and its relation to oral and general health conditions. Oral Dis. 2017;23(7):973-82.

27. Lynge Pedersen AM, Belstrøm D. The role of natural salivary defenses in maintaining a healthy oral microbiota. J Dent. 2019;80(Suppl 1):S3-12.

28. Almståhl A, Wikström M, Fagerberg-Mohlin B. Microflora in oral ecosystems and salivary secretion rates - a 3-year follow-up after radiation therapy to the head and neck region. Arch Oral Biol. 2015;60(9):1187-95.

29. Asakawa M, Takeshita T, Furuta M, Kageyama S, Takeuchi K, Hata J, Ninomiya T, Yoshihisa YY. Tongue microbiota and oral health status in communitydwelling elderly adults. Sphere. 2018;3(4):e00332-18.

30. Caselli E, Fabbri C, D’Accolti M, Soffritti I, Bassi C, Mazzacane S, Franchi M. Defining the oral microbiome by whole-genome sequencing and resistome analysis: the complexity of the healthy picture. BMC Microbiol. 2020;20(1):120.

31. Health and Welfare Bureau for the Elderly. Ministry of Health, Labour and Welfare, Japan; 2016. Long-Term Care Insurance System of Japan. https:// www.mhlw.go.jp/english/policy/care-welfare/care-welfare-elderly/dl/ltcisj_ e.pdf. Accessed July 13, 2021.

32. WHO Oral Health Survey: Basic Methods 5 th edition.

33. Fukushima Y, Sano Y, Isozaki Y, Endo M, Tomoda T, Kitamura T, Sato T, Kamijo Y, Haga Y,Yoda T. A pilot clinical evaluation of oral mucosal dryness in dehydrated patients using a moisture-checking device. Clin Exp Dent Res. 2019;5(2):116-20.

34. Shimizu T, Ueda T, Sakurai K. New method for evaluation of tongue-coating status. J Oral Rehabil. 2007:34(6):442-7.

35. Chalmers JM, King PL, Spencer AJ, Wright FA, Carter KD. The oral health assessment tool -validity and reliability. Aust Dent J. 2005;50(3):191-9.

36. Ohara-Nemoto Y, Ono T, Shimoyama Y, Kimura S, Nemoto TK. Homologous and heterologous expression and maturation processing of extracellular glutamyl endopeptidase of Staphylococcus epidermidis. Biol Chem. 2008;389(9):1209-17.

37. Shimoyama Y, Ishikawa T, Kodama Y, Kimura S, Sasaki M. Tyrosine tRNA synthetase as a novel extracellular immunomodulatory protein in Streptococcus anginosus. FEMS Microbiol Lett. 2020;367(18):fnaa153.

38. Dollive $S, C h e n$ YY, Grunberg S, et al. Fungi of the murine gut: episodic variation and proliferation during antibiotic treatment. PLOS ONE. 2013;8(8):71806.

39. Yoshida A, Suzuki N, Nakano Y, Oho T, Kawada M, Koga T. Development of a 5'fluorogenic nuclease-based real-time PCR assay for quantitative detection of Actinobacillus actinomycetemcomitans and Porphyromonas gingivalis. J Clin Microbiol. 2003;41:863-6.

40. Nomura T, Murakami T, Shimoyama Y, Kobayashi T, Furuya J, Sasaki M, Kondo $\mathrm{H}$. Effects of denture adhesives on growth and morphological transformation of Candida albicans. J Prosthodont Res. 2020;64(1):78-84.

41. Cederholm T, Jensen GL, Correia MITD, et al. GLIM criteria for the diagnosis of malnutrition - a consensus report from the global clinical nutrition community. Clin Nutr. 2019;38(1):1-9.

42. Nishizawa T, Niikura Y, Akasaka K, Watanabe M, Kurai D, Amano M, Ishii H, Matsushima H, Yamashita N, Takizawa H. Pilot study for risk assessment of aspiration pneumonia based on oral bacteria levels and serum biomarkers. BMC Infect Dis. 2019;19(1):761. https://doi.org/10.1186/s12879-019-4327-2.

43. Beck AM, Ovesen L, Osler M. The 'Mini Nutritional Assessment'(MNA) and the 'Determine your Nutritional Health'Checklist (NSI checklist) as predictors of morbidityand mortality in an elderly Danish population. Br J Nutr. 1999;81(1):31-6.

44. Cook Z, Kirk S, Lawrenson S, Sandford S. Use of BMI in the assessment of under nutrition in older subjects: reflecting on practice. Proc Nutr Soc. 2005:64(3):313-7.

45. Nakazawa A, Nakamura K, Kitamura K, Yoshizawa Y. Association between body mass index and mortality among institutionalized elderly adults in Japan. Environ Health Prev Med. 2013;18(6):502-6.

46. Arikawa E, Kaneko N, Nohara K, Yamaguchi K, Mitsuyama M, Sakai T. Influence of olfactory function on appetite and nutritional status in the elderly requiring nursing care. J Nutr Health Aging. 2020;24(4):398-403.

47. Honma T, Hatta K, Hitomi Y, Kambayashi Y, Hibino Y, Konoshita T, Nakamura $H$. Increased systemic inflammatory interleukin-1ß and interleukin-6 during agitation as predictors of Alzheimer's disease. Int J Geriatr Psychiatry. 2013;28(3):233-41.

48. Ogawa T, Hirose Y, Honda-Ogawa M, Sugimoto M, Sasaki S, Kibi M, Kawabata S, Ikebe K, Maeda Y. Composition of salivary microbiota in elderly subjects. Sci Rep. 2018:8(1):414

49. Takeshita T, Yasui M, Tomioka M, Nakano Y, Shimazaki Y, Yamashita Y. Enteral tube feeding alters the oral indigenous microbiota in elderly adults. Appl Environ Microbiol. 2011;77(19):6739-45.

50. Dawes C, Pedersen AM, Villa A, Ekström J, et al. The functions of human saliva: a review sponsored by the World Workshop on Oral Medicine VI. Arch Oral Biol. 2015;60(6):863-74.

51. Carmody RN, Bisanz JE, Bowen BP, et al. Cooking shapes the structure and function of the gut microbiome. Nat Microbiol. 2019;4(12):2052-63.

52. Furtado GE, Uba Chupel M, Minuzzi L, Patrício M, Loureiro M, Bandelow S, Hogervorst E, Ferreira JP, Teixeira AM. Exploring the potential of salivary and blood immune biomarkers to elucidate physical frailty in institutionalized older women. Exp Gerontol. 2020;129:110759.

53. Feller L, Altini M, Khammissa RAG, Chandran R, Bouckaert M, Lemmer J. Oral mucosal immunity. Oral Surg Oral Med Oral Pathol Oral Radiol. 2013;116(5):576-83.

54. Kilian M, Reinholdt J, Lomholt H, Poulsen K, Frandsen EV. Biological significance of IgA1 proteases in bacterial colonization and pathogenesis: critical evaluation of experimental evidence. APMIS. 1996;104(5):321-38. https:// doi.org/10.1111/j.1699-0463.1996.tb00724.x.

55. Grant M, Kilsgård O, Åkerman S, Klinge B, Demmer RT, Malmström J, Jönsson D. The human salivary antimicrobial peptide profile according to the oral microbiota in health, periodontitis and smoking. J Innate Immun. 2019;11:432-43.

56. Wu TY, Liu HY, Wu CY, Chen HC, Huang ST, Chen PH. Professional oral care in end-of-life patients with advanced cancers in a hospice ward: improvement of oral conditions. BMC Palliat Care. 2020;19(1):181. https://doi.org/10.1186/ s12904-020-00684-0.

57. Fanello S, Bouchara JP, Sauteron M, Delbos V, Parot E, Marot-Leblond A, Moalic E, Flohicc AML, Brangerd B. Predictive value of oral colonization by Candida yeasts for the onset of a nosocomial infection in elderly hospitalized patients. J Med Microbiol. 2006;55(Pt 2):223-8.

58. Javed F, Klingspor L, Sundin U, Altamash M, Klinge B, Engstrom PE. Periodontal conditions, oral Candida albicans and salivary proteins in type 2 diabetic subjects with emphasis on gender. BMC Oral Health. 2009;9:12. https://doi. org/10.1186/1472-6831-9-12.

59. Everest-Dass AV, Jin D, Thaysen-Andersen $M$, Nevalainen $H$, Kolarich $D$, Packer $\mathrm{NH}$. Comparative structural analysis of the glycosylation of salivary and buccal cell proteins: innate protection against infection by Candida albicans. Glycobiology. 2012;22(11):1465-79.

60. Khan SA, Fidel PL Jr, Thunayyan AA, Varlotta S, Meiller TF, Jabra-Rizk MA. Impaired Histatin-5 levels and salivary antimicrobial activity against in HIV Infected individuals. J AIDS Clin Res. 2013;4(193):1000193.

61. Jenkinson HF, Lala HC, Shepherd MG. Coaggregation of Streptococcus sanguis and other streptococci with Candida albicans. Infect Immun. 1990;58(5):1429-36.

62. Diaz P, Xie Z, Sobue T, Thompson A, Biyikoglu B, Ricker A, lkonomou L, Dongari-Bagtzoglou A. Synergistic interaction between Candida albicans and commensal oral streptococci in a novel in vitro mucosal model. Infect Immun. 2020;80(2):620-32. 
63. Samaranayake LP, MacFarlane TW. Factors affecting the in-vitro adherence of the fungal oral pathogen Candida albicans to epithelial cells of human origin. Arch Oral Biol. 1982;27(10):869-73.

64. Pereira-Cenci T, Deng DM, Kraneveld EA, Manders EM, Del Bel Cury AA, Ten Cate JM, Crielaard W. The effect of Streptococcus mutans and Candida glabrata on Candida albicans biofilms formed on different surfaces. Arch Oral Biol. 2008;53(8):755-64.

65. Mokhtar M, Rismayuddin NAR, Mat Yassim AS, Ahmad H, Abdul Wahab R, Dashper S, Arzmi MH. Streptococcus salivarius K12 inhibits Candida albicans aggregation, biofilm formation and dimorphism. Biofouling. 2021;23:1-10.

\section{Publisher's Note}

Springer Nature remains neutral with regard to jurisdictional claims in published maps and institutional affiliations.
Ready to submit your research? Choose BMC and benefit from:

- fast, convenient online submission

- thorough peer review by experienced researchers in your field

- rapid publication on acceptance

- support for research data, including large and complex data types

- gold Open Access which fosters wider collaboration and increased citations

- maximum visibility for your research: over $100 \mathrm{M}$ website views per year

At BMC, research is always in progress.

Learn more biomedcentral.com/submissions 